\title{
Migrantes e refugiados: à (a) espera de uma narrativa?
}

\author{
Migrants and refugees: waiting for a narrative? \\ Leonardo Tonus \\ Sorbonne Université. Paris, França.
}

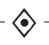

\begin{abstract}
Resumo: O mundo tem presenciado nas últimas décadas o maior fluxo de deslocamentos migratórios de sua história desde a Segunda Guerra Mundial. Não se passa um dia sem que a imprensa nacional ou internacional anuncie o desaparecimento de migrantes pelos oceanos do planeta, o desmantelamento de campos "selvagens" de estrangeiros ou a implementação de novos dispositivos jurídicos de gestão de populações expatriadas. Da invisibilidade do final dos anos 90 à inflação atual de textos, migrantes e refugiados tornaram-se nestas últimas décadas atores inconturnáveis do campo midiático e literário. O presente artigo visa interrogar as formas de representaçã desta nova categorial social na produção literária brasileira contemporânea.

Palavras-chave: refugiados; invisibilidade; representação.
\end{abstract}

\begin{abstract}
In recent decades, the world has witnessed the greatest migratory movements in its history since World War II. Not a day passes without the national or international press reporting the disappearance of migrants on the oceans of the planet, the dismantling of 'wild' camps of foreigners, or the implementation of new legal devices for the management of emigrants. From the invisibility of the 1990's to the current escalation in the number of texts, migrants and refugees have become major players in the media and literary field. This article reflects upon the form of representation of this new social category in Brazilian modern literature.

Keywords: refugees; invisibility; representation.
\end{abstract}

O mundo tem presenciado nas últimas décadas o maior fluxo de deslocamentos migratórios de sua história desde a Segunda Guerra Mundial. Segundo dados fornecidos pela Agência da ONU para refugiados cerca de 68,5 milhões de pessoas em todo o mundo já foram forçadas a deixarem seus lares. Entre elas estão quase 25,4 milhões de refugiados, sendo mais da metada com menos de 18 anos. Até $1^{1}$ de Dezembro de 2018, 131.339 pessoas teriam migrado em direção à Europa por via marítima (107,216 pessoas) ou terrestre $(24,123 \text { pessoas })^{1}$. Os dados apontam para um nítido decréscimo do contigente migrante que, em 2016, teria atingido o número de 390.432 chegadas. Apesar desta mudança, decorrente de medidas auteras implantadas pelos governos europeus no que tange ao acolhimento de estrangeiros, o número de mortos e desaparecidos no

\footnotetext{
1 ACNUR. Disponível em: <https://www.acnur.org/portugues/>. Acesso em: 23 out. 2018.
}

Mediterrâneo continua elevado: 2.123 pessoas em 2018, 3.116 em 2017 e 5.143 no ano de 2016. É neste sentido, e a fim de alertar a opinião pública sobre a crise migrante, que jornal alemão Der Spiegel publicava em novembro de 2017 em sua folha dominical uma extensa lista que compreendia mais de 48 páginas e nas quais detalhava os dados disponíveis acerca dos afogamentos de refugiados e migrantes entre entre 1993 e maio de 2017, p. 33.293 pessoas, muitas das quais aparecem sob a intitulação de "N.N." (para "nomen nescio" = nome desconhecido) ${ }^{2}$.

Em proporções menores o Brasil tem sido igualmente destino de deslocamentos migratórios. Em dez anos o número de imigrantes registrados pela Polícia Federal teria aumentado $160 \%$, contabilizando a entrada de 117.745 estrangeiros em 2015. Como em outras partes do planeta a presença deste contigente estrangeiro se explica

\footnotetext{
2 Tagesspiel. Disponível em: < https://www.tagesspiegel.de/downloads/ 20560202/3/listeentireberlinccbanu.pdf $>$. Acesso em: 20 nov. 2018.
} 
por diversas motivações: catástrofes naturais (Haitianos), guerra (Sírios), opressão política (Congoloses, Nigerianos e Venezuelanos) e busca de melhores condições de vida ( Bolivianos).

O Brasil é país signatário dos principais tratados internacionais de direitos humanos nomeadamente da Convenção das Nações Unidas de 1951 sobre o Estatuto dos Refugiados e do seu Protocolo de 1967. Em julho de 1997, o país promulgou a sua lei de refúgio (no 9.474/97), que contempla os principais instrumentos regionais e internacionais sobre o tema. Esta lei adota a definição ampliada de refugiado estabelecida na Declaração de Cartagena de 1984, que considera a "violação generalizada de direitos humanos" como uma das causas de reconhecimento da condição de refugiado.

Para administrar a questão relativa ao refúgio o Brasil dispõe do Comitê Nacional para os Refugiados (CONARE), um órgão interministerial presidido pelo Ministério da Justiça e que lida principalmente com a formulação de políticas para refugiados no país. A lei garante documentos básicos aos refugiados, incluindo documento de identificação e de trabalho, além da liberdade de movimento no território nacional e de outros direitos civis. De acordo com os dados do CONARE, do Ministério da Justiça e Segurança Pública, o Brasil teria conhecido em 2016 um aumento de $12 \%$ no número total de refugiados reconhecidos e recebido, entre 2010 e 2017 , 126.127 solicitações de reconhecimento da condição de refugiado, a maior parte delas por venezuelanos ${ }^{3}$.

Dentro do panorama geral das migrações internacionais a situação brasileira surge como relativamente estável o que não impediu o governo adotar, à imagem de outros países, medidas drásticas em matéria da política de acolhimento, integração ou de refugo de estrangeiros. Estas visam tanto assegurar a sobrevivência e a segurança física, alimentar e sanitária como o controle de populações cada vez mais fragilizadas, indesejadas e socialemente invisíveis, apesar do impacto mediático, científico e editorial que migrantes e refugiados têm suscitado nos últimos anos.

Não se passa um dia sem que a imprensa nacional ou internacional anuncie, relate ou comente o desaparecimento de grupos de migrantes pelos mares e pelos oceanos do planeta, o desmantelamento de campos "selvagens" de estrangeiros ou a implementação de novos dispositivos jurídicos de gestão condicionados a interesses políticos, partidários ou ideológicos. Por outro lado a multiplicação de palestras, jornadas de estudos, colóquios e publicações científicas testemunha o crecente interesse da academia sobre esta questão. $\mathrm{Na}$ esteira

\footnotetext{
3 Ministério da Justiça. Disponível em: $<$ http://justica.gov.br/seus-direitos/ estrangeiros/refugio/conare>. Acesso em: 20 nov. 2018.
}

da criação do "Refugees Studies" do Departamento de Desenvolvimento internacional da universidade de Oxford em 1982 diversas instituições universitárias criaram centros de formação e pesquisa especializados na questão das migrações internacionais contemporâneas, do refúgio e das fronteiras internacionais. A título de exemplo, podemos citar, entre outras, o "Center for migration and refugees studies" da Universidade americana do Cairo, o Laboratório de Investigação em Migração, Nação e Fronteira (LIMINAR) da UNifesp ou ainda Global Refugee Studies da Aalborg University de Copenhagen, um MBA internacional de dois anos que visa criar para os estudantes oportunidades de trabalho em organizações governamentais internacionais e nacionais e organizações não-governamentais onde o trabalho analítico e estratégias sobre questões de refugiados e migração são centrais ${ }^{4}$.

A crise humanitária relativa à condição do refúgio também conduzido a um engajamento cada vez maior por parte da cena artística mundial. Perfomances, exposições, filmes, documentários, peças de teatros multiplicam-se pelo mundo investindo o simbólico no sentido de alterizar o nosso olhar sobre uma questão cuja crueldade diaria e corriqueira passamos a nos habituar. Alguns eventos marcantes de 2015 e 2016 comprovam esta hipótese.

\section{Da sideração à consideração}

Até ao verão de 2015, migrantes e refugiados era um problema dos chamados países tampão, em que os estados do Norte da Europa se mantinham à margem. $\mathrm{O}$ número crescente de pessoas chegadas à Turquia e à Grécia, por um lado, e a situação caótica vivida nos países do Leste, em particular a Hungria, por outro, contribuíram de maneira significativa a alterar este quadro e a captar o foco da mídia internacional sobre a questão. A cobertura midiática atinge o seu pico com o falecimento morte do sírio Alan Kurdi, o pequeno Aylan, cuja fotografia foi destaque internacional nos dias 3 e 4 de setembro de 2015. A partir desta foto, a personalização do drama dos migrantes e refugiados passou a ser um elemento presente

\footnotetext{
4 Segundo a brochura explicativa: "Today Western development aid is increasingly directed at initiatives related to refugees. The idea is that development aid should be directed to the countries and regions that 'generate' migrants and refugees in order to create new circumstances to ensure that refugees and forced migrants remain in the close neighbourhood either in the countries of origin or the surrounding countries. There is a serious lack of knowledge about the impact of this and many other initiatives on the actual situation of global, regional and local refugees. This study programme will add to bridge the gap of the missing knowledge about the status of forced migration. The Danish and European debate regarding refugees has changed radically in the past few years. From an almost exclusive focus on assimilation and integration it has now turned into both a security and foreign policy". Aalborg University. Disponível em: <https://www.aau.dk/ digitalAssets/242/242536_grs-2015.pdf>. Acesso em: 20 set. 2018.
} 
na cobertura jornalística que acaba por despertar a opinião pública para o conflito no território sírio. $\mathrm{O}$ outro pico de informação ocorre alguns dias mais tarde quando a cinegrafista húngara Petra Laszlo, buscando uma imagem "choque", agride um migrante que fugia da polícia com uma criança ao colo. Num e no outro caso, as imagens espalharam-se antes pelas redes sociais não resistindo à pressão da opinião pública. Numa onda de solidariedade sem precedentes, as diferentes reportagens realizadas na altura tiveram forte um impacto nas agendas política e pública. Elas transformam radicalmente a percepção mundial da crise dos refugiados e migrantes que, no entanto, diante da repetição do drama se interrompe.

Na noite de 29 e 30 de janeiro de 2016 um barco naufragava no mar Egeu a algumas centenas de metros da costa turca. Os tripulantes a bordo, compostos de refugiados sírios, iraquianos, afgãos, birmanos tentam se salvar nadando até a ilha de Lesbos. 37 morrerão afogados dos quais muitas crianças. Dois dias antes 24 pessoas das quais 10 crianças morriam afogadas realizando o mesmo trajeto. O fotojornalista da Agência Francesa de Imprensa (AFP), Ozan Kose conta num dos post de seu blog a situação na altura presenciada:

Quand j'arrive sur la plage de galets, le premier cadavre que je vois est celui d'un bébé. Il doit avoir 9 ou 10 mois, il est chaudement couvert et porte un bonnet. Une tétine orange est accrochée à ses habits. A côté de lui gisent un autre enfant, âgé de 8 ou 9 ans, ainsi qu'une adulte, leur mère peut-être. Sur le moment, je ne sais pas quoi faire. Je prends quelques photos. Je parcours la plage, je vois le corps d'un autre enfant sur un rocher. Par la suite je ferai des cauchemars, je serai durant des heures incapable de parler, mais à cet instant je ne ressens rien de particulier (KOSE, p. 2018). ${ }^{5}$

Se a foto destas e de tantas outras crianças mortas durante a tragédia das últimas migrâncias ainda emociona e"sidera" a opinião pública, ela já não suscita compaixão. Como sublinha a filósofa francesa Marielle Macé:

La sidération s'accompagne d'une sorte de paralysie, ou d'un recul - un recul devant quelque chose qui reste alors de l'ordre d'un spectacle, plus ou moins lointain, spectral, quelque chose avec quoi on maintient une distance profonde, avec quoi on ne parvient

\footnotetext{
5 "Quando cheguei na praia de cascalhos, o primeiro cadavre que vejo é o de um bebê. Ele deve ter entre 9 e 10 meses e esta vestido com roupas quentes e um gorro. Uma chupeta laranja está colada a suas roupas. Ao seu lado jaz uma outra criança de 8 ou 9 anos e um adulto, talvez a sua mãe. Não sei o que fazer naquele momento. Tiro algumas fotos. Ando pela praia. Vejo o corpo de uma outra criança num rochedo. Depois disso terei vários pesadelos e ficarei horas sem poder falar, mas naquele exato momento eu não sentia nada em particular" (minha tradução).
}

pas à avoir de rapport: quelque chose qui arrête en fait en nous la possibilité de la pensée, et du partage (MACE, p. 2017). ${ }^{6}$

Face ao terror, o processo psicológico o esturpor da "primeira vez" dissocia o circuito emocional de suas funções cognitivas, impedindo a tomada de consciência que com a repetição do gesto acaba por desaparecer. Em outros termos, o efeito do esturpor atenua-se neutralizando, posteriormente, os reflexos que desencandeiam sentimentos como a compaixão, a cólera ou simplesmente o desejo de compreensão. É contra o esquecimento desta memória traumática e repetitiva que o ilustrador mexicano Eduardo Salles (2018) publicava neste mesmo ano um desenho onde se via o corpo do menino Aylan apagar-se com o tempo. Embaixo da ilustração, ele anotava: "a memória coletiva é sempre a curto prazo"7.

Num registro mais polêmico de denúncia da banalização da violência e do seu esquecimento, o artista chinês Ai Weiwei pousava no início de 2017 ano para o fotógrafo Rohit Chawla em uma praia da ilha grega de Lesbos, local de desembarque de milhares de migrantes. A foto remete imediatamente à imagem traumática do garoto afogado, mas provoca estranhamento ao propor uma leitura com o grotesco e o obsceno. Em lugar do menino exibido pelas mídias socias em diversas ilustrações posteriores ainda vivo, saudável e alegre, a figura do artista é contrastante e repulsiva: um adulto com sobrepeso, oriental, de barba longa e parcialmente grisalha. Se em lugar da simpática criança, alguém de figura similar a de Weiwei tivesse morrido, teria igualmente passado desapercebido e anônimo como qualquer uma das já mencionadas 33.963 pessoas mortas ou desaparecidas no Mediterrâneo entre 1993 e 2017 . A imagem produzida inscreve-se num engajamento do artista que desde o início da crise dos refugiados e migrantes relata a tragédia humana em sua conta Instagram via les hashtags \#refugees ou \#safepassage. Em sua proposta, Weiwei critica a ambivalente capacidade contemporânea de se comover, mas também de ignorar, o sofrimento alheio, de conviver indiferentemente em meio a tantas outras mortes ocorridas no legítimo direito humano de escapar de uma zona de conflito, de almejar uma vida melhor, sobreviver. A imagem do artista chinês apela por uma responsabilidade ética e moral da sociedade (e da

\footnotetext{
6 “A sideração se acompanha de um tipo de paralisia, ou de volta para trás - uma volta para trás diante da coisa que permanece ela própria vinculada ao espetáculo, mais ou menos distante, mais ou menos espectral, algo com o que se mantém uma distância profunda, com o que não se consegue ter qualquer relação: algo que interrompe em nós a possibilidade de pensar, de compartilhar" (minha tradução).

7 Eduardo Salles.@sallessino. Disponível em: <https://twitter.com/ sallesino>. Acessível em: $10 \mathrm{dez} .2018$.
} 
arte) diante da realidade da experiência culturalmente traumática ${ }^{8}$.

Encontramos um questionamento semelhante na realização da performance dos artistas Justus Becker e Oğuz Şen que, em homenagem a Aylan, realizam, em março de 2017, um grafite de mais 20 metros a dois passos do Banco Central de Frankfurt. Mais do que a questão do dever da memória pela mostração da morte, a performance artística visa aqui à desconstrução do olhar hegemônico do sujeito observador. Tal efeito é produzido pela alteração da escala e pela mudança do ponto de vista. Passamos da visão em "plongée" da fotografia inicial a um perpsectiva em "contre-plongée" que fragiliza o sujeito observador diante da monstruosidade da morte. O espaço a partir do qual a cena é observada propõe igualmente uma inversão de papéis. Contrariamente à criança, é o sujeito observador que se situaria no espaço aquático sugerindo, como se afogado, a ideia de uma "morte com" sem qual o sentimento mesmo de empatia e da compaixão deixam de ser operantes ${ }^{9}$.

Desde 2015, a foto de Aylan Kurdi configura em si uma imagem de síntese traumática que agrega valores e referências em relação a temas universais como a morte e a infância. Por outro lado, ela aponta para desdobramentos possíveis de caráter mais ideológico (e por vezes controverso), tais como a necessidade e/ou obrigatoriedade de acolhimento humanitário, a injustiça e a desigualdade de oportunidades e condições em um mundo globalizado, o dilema entre capacidade, vontade e escolha por atuar

\footnotetext{
8 \#SafePassage será posteriormente apresentado no Foam photography museum de Amsterdam. A exposição compõe-se de 15.600 fotografias realizadas pelo artista durante suas visitas a campos de refugiados espalhados em Lesboas aquando do resgate de migrantes. A entrada da instalação apresenta um auto-retrato de Ai Weiwei, em pé na beira do mar, segurando uma placa com o texto: "\#SafePassag". Os demais espaços são cobertos por fotografias de pessoas em deslocamento na Grécia, Turquia, Alemanha, Líbano, Gaza, Jordânia, Israel e Quênia (o trabalho é chamado de "Iphone Wallpaper"). Elas mostram refugiados e remanescentes de suas viagens: barcos de borracha, acampamentos improvisados, pessoas envolvidas em cobertores térmicos, rostos de refugiados em close testemunhando esperança, resiliência e desespero. Entre as fotografias há regularmente selfies do artista com refugiados, com voluntários ou profissionais que trabalham com estes. Se pela quantidade excessiva de fotografias apresentadas o artista explora a amplitude real e imaginada da crise migratória, o emprego do selfie busca estabelecer uma relação afetiva com o público e conceder voz àqueles que não a têm por se inserirem no âmbito da clandestinidade. Mas a pergunta permanece: a simples mostração do subalterno é capaz de proporcionar a capacidade de "falarem por si mesmos" e, deste modo, "representarem uma situação" com sinceridade? De fato, se o artista confere-lhes voz denunciando o descaso das autoridades européias diante desta tragédia humanitária, a participação ativa do sujeito subalterno no processo de criação é limitada. Todo processo de represetação ainda é liderado pela voz autoral que continua a falar "para" e "pelos" subalternos, mediante um trabalho que nos questiona acerca dos limites éticos da utilização da imagem para fins artísticos ou sensasionalistas que se servem, estrategicamente, das ocorrências traumáticas para impactar o público ou aumentar o número de leitores e visualizações.

9 Eulen Fish, "Es ist ein Gedenkbild ». Disponível em: <http://www. eulenfisch.de/magazin/ausgaben/01-2016-flucht-in-die-fremde/ouz-enund-justus-cor-becker-im-gespraech-es-ist-ein-gedenkbild/>. Acesso em: 10 dez. 2018
}

em uma situação de crise, bem como a invisibilidade dos sujeitos subalternizados. As reações suscitadas diante da imagem original - repetição, apropriação e recriação constituem, assim, indícios testemunhais de um trauma mas cuja efemeridade e superficialidade são latentes. A tentativa de superação face ao inenarrável, o desejo de compartilhamento, o apelo ao dever da memória fixamse em elementos dependentes antes do consumo midíaco rápido e globalizado.

\section{O espetáculo migrante}

A narrativa das novas migrâncias conhece uma longa tradição junto à imprensa e a outros veículos de comunicação de massa. As contradições há pouco evocadas (sublimação ou banalização do mal; espetacularização ou apaziguamento do trauma) também ganham terreno na cena literária onde migrantes e o refugiados vivem uma paradoxal visibilidade. Da invisibilidade do final dos anos 90 à inflação atual de textos sobre os deslocamentos mundiais, migrantes e refugiados tornaram-se nestas últimas décadas atores inconturnáveis do campo literário. As migrâncias se tornaram hoje, no âmbito internacional, um verdadeiro fenômeno literário e editorial, ambos vinculados a estratégias de marketings e dos processos de espetacularização de que se nutre a cena literária.

O portal francês Babélio indica mais de 1700 publicações ( romances, romances gráficos, literatura infantil ou juvenil) sobre a questão do refúgio. Projetos literários em torno de refugiados multiplicam-se pelo mundo ("Refuees worldwold", "Look", "Ankunft") conferindo visibilidade a artistas oriundos da migrância. Sua presença no Festival de Literatura internacional de Berlim de 2016 e 2017, no Salão do livro de Paris de 2017, na Feira de Frankfurt de 2015 e até na FLIP comprovam este interesse cada vez maior por parte do campo artístico e do público em geral.

Abud Said veio a Flip de 2016 para apresentar o seu livro O Cara Mais Esperto do Facebook (Editora 34). Este reúne alguns de seus posts redigidos entre 2009 e 2013; uma mistura de diário, comentários sarcásticos sobre a vida e observações irônicas. O livro acompanha a vida do autor na Síria antes da guerra civil iniciada em 2011 e continua pelos primeiros anos do conflito, até chegar a 2013, quando sua fama virtual dá origem a um e-book, lançado primeiramente na Alemanha. Na Flip, Said participou da mesa intitulada "Síria mon amour" acompanhado pela repórter Patrícia Campos Mello, especialista na cobertura de áreas em conflito geopolítico. No início da conversa o público parecia apreciar o seu jeito irônico brincalhão e modesto. Como sublinha matéria no Jornal $O$ globo: 
No começo, o povo curtiu. Com seu tipo "nem aí" irônico, que brinca de ser excessivamente autoconfiante e modesto ao mesmo tempo, o autor fez sucesso. Arrumou até um jeito de alterar seu status para "solteiro" quando Patrícia se referiu a uma suposta namorada dele ("apenas uma amiga", assegurou o convidado) (MURARO, p. 2018).

A polêmica surge quando o escritor se nega a falar do conflito sírio e passa a ironizar e criticar a instrumentalização da questão do refúgio pelas mídias, pelos intelectuais e até pelo próprio campo literário. Segundo o próprio autor:

O jornalismo, a mídia, as organizações de direitos humanos, o conselho da ONU, os escritores, todos eles estão fazendo um jogo sujo. Eu não gostaria de participar desse jogo. O Estado Islâmico é um assunto muito importante, não quero agora falar quem é o Estado Islâmico. Não tenho medo, mas não quero participar desse jogo sujo. Todo mundo parece que está participando, de uma forma ou de outra, sob bandeiras de mídia livre, de direitos humanos, não existe mídia livre, tem gente ganhando dinheiro com isso". [...] "Estou feliz comigo mesmo, não quero ser a voz da Síria nem a voz dos direitos humanos, faz três anos que cansei dos direitos humanos, ou de falar de cultura, Estado Islâmico... Há três anos estou nessa roda. Juro por Deus que não há sociedade mais doente que a sociedade culta, intelectual, esse pessoal que trabalha com direitos humanos, são eles que precisam de gente para resolver seus problemas (MURARO, p. 2018).

A espetacularização da figura autoral passa, como sabemos, pela fetichização de seu discurso. Mais importante do que ser entendido, debatido, até mesmo contestado, a presença do escritor tem por função chamar a atenção para a "persona" do autor sobretudo quando esta se acompanha de polêmicas capazes de estreitar as velhas fronteiras entre publicidade e privacidade. A exposição de elementos da vida privada, estratégia cada vez mais recorrente no universo literário, desloca as informações dos bastidores para as fachadas. Os novos suportes de que se servem e que compõe o campo literário converte o espaço privado do autor em mercadoria, o escritor sendo então capaz espaço de oferecer produtos atractivos que despertem a curiosidade de um público consumidor de produtos culturais de carácter cada vez mais lúdicos: no caso, a guerra da Síria e as aventuras migrantes.

Ora, se os atores do campo literário internacional têm demonstrado um interesse cada vez maior pela questão dos refugiados, no Brasil migrantes e refugiados permanecem praticamete ausentes da nossa literatura. Nostálgicos e exóticos relatos de imigrantes do início do século XX continuam a compor as listas dos nossos principais prêmios literários. Os autores nacionais tendem cada vez mais a expatriarem suas vozes e personagens para o espaço exógeno. Muitas visitam a Grécia sem esbarrarem pelos campos de retenção de migrantes nas paradisíacas ilhas do mar Egeu. Outras viajam com frequência a Paris. Caminham pelo Champs Elysées. Visitam museus e comentam sua relação com os grandes clássicos da literatura e cultura francesas. Algumas até tomam Eurostar em direção a Londres esquecendo-se, no entanto, de voltar seus olhos para a selva de Calais e outros tantos muros que separam nossas fronteiras quase inexistentes. Até as vozes periféricas de nossas grandes metrópoles permanecem ainda alheias aos sotaques haitianos, congoleses ou angolanos que se aglomerarem nos cortiços e nos arredores de nossas grandes capitais. Quem e quantos são os autores que hoje abordam a questão do refúgio e da migrância no Brasil? Nenhum, ou quase. Um rápido mapeamento realizado nos últimos meses pela consulta dos catálogos das grandes editoras brasileiras ou de sites ligados à Ongs que trabalham com a migrância e a refúgio, nos conduz a dados assustadores se levarmos em conta suas lacunas ${ }^{10}$. Como explicar tal silenciamento, sobretudo num país em que o tema da imigração ainda participa de sua narrativa identitária e que não se desfez do velhos mitos da cordialidade e de fraternidade entre os povos? Seria este silêncio decorrente de um autocentramento que nos últimos tempos têm-se acentuado face às crises econômicas, sociais e institucionais que o Brasil tem presenciado ? Ou estariam migrantes e refugiados fadados, como outras tantas minorias no país, ao estatuto de clandestinos em relação a uma cena literária marcada por uma perspectiva social enviesada? Como sugere a professor e pesquisadora Regina Dalcastagné:

Falta ao romance brasileiro dos últimos quinze anos, incorporar as vivências, os dramas, as opressões, mas também as fantasias, as esperanças e as utopias dos grupos sociais subalternos, sejam eles definidos por classe, por sexo, por raça e cor, por orientação sexual ou por qualquer outro critério. [...] nossa literatura apresenta uma perspectiva social enviesada, tanto mais grave pelo fato de que os grupos que estão excluídos da voz literária são os mesmos que são silenciados nos outros espaços de produção do discurso - a política, a mídia, em alguma medida ainda o mundo acadêmico (DALCASTAGNÈ, p. 2005).

\section{Clandestinidades e esperas}

O vasto campo de aplicação jurídico, político, sociológico e filosófico vinculado ao conceito de clandestinidade tende a associar esta prática a atividades

\footnotetext{
${ }_{10}$ Trata-se de uma pesquisa ainda em andamento com resultados parciais. A ausência desta temática na recente literatura no Brasil é, no entanto, problemática.
} 
ilícitas que posicionam seus atores para além da esfera da legalidade. Que se trate de oponentes a regimes políticos, imigrantes ilegais, refugiados, contrabandistas, traficantes ou terroristas, todas estas figuras compartilham entre si uma territorialidade extraviada que, resultante de uma ruptura com o espaço centralizador, priva o sujeito de um lugar habitável e fixo. A clandestinidade é, como uma prática do minoritário que inscreve o sujeito no universo da fração.

O estado de clandestinidade implica um deslocamento voluntário (ou involuntário) do sujeito em direção de um espaço que o abriga temporaria ou definitivamente e com o qual ele estabelece relações de inclusão e exclusão, de vizinhança e distanciamento, de proximidade e de lateralidade. A contradição do estado de clandestinidade repousa justamente nesta relação metonímica que o sujeito entretem com espaço de que é oriundo e com aquele que passa a residir. Esta implica uma conexão de contiguidade entre dois significantes com as quais o clandestino tem constantemente de negociar. Em outras palavras, a clandestinidade induz a uma dupla territorialidade em função da qual se elaboram as condições e de existência e de sobrevivência do sujeito. É a partir desta dupla espacialidade que o clandestino nãoautorizado elabora e administra um espaço de liberdade cuja independência possibilita-o resistir.

Assim, tornar-se clandestino não significa necessariamente inscrever-se na marginalidade. A clandestinidade constitui menos a evasão do sujeito do que a modificação de uma subjetividade em relação aos espaços que frequenta, sejam eles centrais, estáveis, periféricos ou marcados pela precariedade (aeroportos, squats, campos de refugiados, artefatos literários censurados etc.). Contrariamente aos excluídos cuja "extração territorial" presupõe uma visibilidade pela exposição dos procedimentos de estigmatização, o clandestino encarna uma forma radical de invisibilidade. Toda a sua existência organiza-se em função de um anonimato que, imposto e praticado cotidianamente, visa a não-revelação de sua diversidade em praça pública. No universo da clandestinidade a experiência da alteridade é nula, uma vez que o não-reconhecimento legal do sujeito nega-lhe a possibilidade de se tornar "outro". Ao apagar os rastros deixados pelos espaços que transita, o clandestino, que encarnam atualmente as figuras do refugiados e dos migrantes, prenuncia a do estrangeiro e se apresenta, assim, como uma não-figura cuja ausência legal certifica sua permanência temporária ou efêmera no espaço, desarticulando a tradicional oposição entre "lugares" e "não-lugares. "Não-figura" do "sem-lugar", migrantes e refugiados habitam os interstícios dos espaços antropológicos fomentores de identidades e aqueles marcados pelas perdas dos marcos identitários: centros de retenção, zonas de trasição, campos de refugio e de trabalho, etc.

O sistema de "encampamento" constitui um dos emblemas centrais da experiência da migrância e do refúgio de nossa contemporaneidade confrontada a uma verdadeira banalização dos lugares de retenção. Nesta nova paisagem mundial que os campos de retenção propõem, ginásios esportivos, instalações industriais desativadas, hangares e corredores de aeroportos têm-se convertido em espaços anônimos à margem da ordem jurídica onde se dá a intersecção do Estado de direito com aquilo que atenta contra ele. Segundo estimativas das organizações internacionais, mais de 12 milhões de pessoas viveriam hoje em campos de trânsito e 6 millhões delas em acampamentos selvagens localizados em florestas, bosques, terrenos baldios ou zonas fronteiriças de cidades e países, sem qualquer controle ou assistência possível.

Elaborados inicialmente enquanto dispositivos de proteção face a uma urgência, os campos de retenção tornaram-se hoje espaços parodoxais nomeadamente no que tange à propria noção de urgência. Sua duração, difícil a ser determinada até do ponto de vista dos próprios agentes das organizações humanitárias, estende-se por períodos intermináveis que vêm alterar o papel ao que se destinavam originalmente, a relação com seus beneficiários e a que estes mantém com o tempo e espaço em que se encontram. Nos campos de retenção, migrantes e refugiados vivem o tempo e o espaço da espera. Segundo Michel Augier:

L'injonction urgentiste impose en outre aux travailleurs des ong internationales d'avoir toujours quelque chose d'urgent à faire; un empressement qui contraste avec la lenteur qui caractérise le rythme des réfugiés dans les camps. La lenteur est, elle, la forme visible de plusieurs états possibles chez les réfugiés "encampés" depuis plusieurs années: souffrance, ennui ou mélancolie attachée au lieu perdu et à l'incertitude du devenir, tissage de nouveaux liens sur place, transformation des habitations. Dans le présent suspendu de la vie des camps, se croisent ainsi les humanitaires expatriés qui s'affairent dans une urgence sans fin, et les réfugiés qui essaient de se repérer et de se refaire une vie dans ces nouveaux lieux et dans la lenteur (AGIER, 2008, p. 10). ${ }^{11}$

\footnotetext{
11 “A injunção urgentista impõe aos trabalhadores das Ongs internacioanis terem sempre algo urgente a fazer. Uma pressa que contrasta com a lendidão que caracteriza o ritmo dos refugiados nos campos. A lentidão é, por sua vez, a forma visível de vários sentimentos possíveis nos refugiados 'encampados' há anos: sofrimento, tédio ou melancolia vinculada ao país perdido ou à incerteza do futuro; estabelecimento de novas relações, transformação das habitações. No presente suspenso da vida dos campos, cruzam-se, deste modo, expatriados apressados numa urgência sem fim, e os refugiados que tentam encontrar-se ou refazer uma vida nestes novos lugares da lentidão" (minha tradução).
} 
Ao transformar o sujeito refugiado em vítima, o sistema humanitário que subjaz à existência dos campos de retenção induz a não existência social e política do seus beneficiários. A espera que lhes é imposta, no entanto, acaba por criar oportunidades de encontros, trocas e de reelaborações identitárias. Ao transformarem simples territórios da espera em espaços sociais, os dispositivos do "encampamento" tornam-se ambiguamente produtores de cidade. Eles permitem a reinvenção do cotidiano sem que se possibilite a apropriação e a transformação das estruturas de poder que os regem. Tais questões são amplamente debatidas no premiado romance infantil $O$ Cometa é um sol que não deu certo de Tadeu Sarmento, uma dos raros textos da literatura brasileira contemporânea a evocar a questão do refúgio.

A história acompanha o cotidiano de um menino sírio cuja família, fugida dos conflitos armados entre rebeldes e as tropas militares durante a Primavera Árabe, se encontra num campo de refugiados no deserto da Jordânia. Sem cair nas armadilhas de um ditatismo excessivo, o romance evoca as condições precárias de habitação no campo, bem como os dilemas da condição da espera que caracterizaria o refugiado: a espera de poder beneficiar de um abrigo que o aprisiona. Como evoca o narrador no início do romance:

O campo está lotado. Emanuel, no alto da colina ao norte, vê a imensidão de pessoas do lado de fora. [...] Toda aquela gente espera pela chance de réfúgio. Atrás das cercas de arame farpado, elas imploram para entrar. [...] Dentro do campo, as pessoas também esperam. Aguardam ansiosas as portas do mundo se abrirem para recebê-las (SARMENTO, 2017, p. 20).

Ora, é justamente neste espaço limiar precário da espera que se opera no texto o engajamento do sujeito em relação ao gesto à alteridade. Próximo à figura do "écart", o espaço-espaçamento do campo surge no romance como lugar da fecundidade, segundo a definição proposta pelo filósofo francês François Julien:

L'écart ne donne pas à poser une identité de principe ni ne répond à un besoin identitaire; mais il ouvre, en séparant les cultures et les pensées, un espace de réfléxivité entre elles où se déploie la pensée. C'est, de ce fait, une figure, non de rangement, mais de dérangement, à vocation exploratoire: l'écart fait paraître les cultures et les pensées comme autant de fécondités (JULIEN, 2012, p. 33). ${ }^{12}$

\footnotetext{
12 "O desvio [écart] não dá origem a uma identidade de princípio nem responde a uma necessidade de identidade; mas abre, separando as culturas e os pensamentos, um espaço de reflexividade entre eles onde o pensamento se desdobra. É, portanto, uma figura, não da tranquilidade, mas da perturbação exploratória: o desvio faz aparecer culturas e pensamentos como fertilidade. [...] Pela distância aberta, ele [o desvio] permite um face a face recíproco de um pelo outro: onde se descobre a si mesmo no olhar do outro, a partir do outro, separando-se dele" (minha tradução ).
}

Ao transbordar a visão tradicional das fronteiras em termos de pontos de contato e de separação, o campo de refugiados é aqui um espaço ambivalente. Por um lado, ele testemunha as novas modalidades de distribuição do poder, de gestão da cidadania e de controle de acesso à mobilidade das populações que caracterizam a nossa contemporaneidade. A figuração do campo de refugiados reforça a territorialização do sujeito em situação de exclusão conformando-o (e confirmando) às suas atribuições identitárias. Por outro lado, ele anula as velhas significações de espaço e de fronteiras que aqui já não fazem sentido. Na zona da transitoriedade que o campo incarna, a fronteira deixa de ter sua lógica horizontal para adquirir uma dinâmica vertical. Os não-lugares tornam-se espaços de criação de afetividade, mediante uma dinâmica da espera que, ao mesmo tempo, aprisiona e liberta o sujeito-refugiado, a voz actorial, e, de certo modo, a literatura brasileira ainda à espera de narrativas sobre esta questão.

\section{Referências}

AGIER, M. Gérer les indésirables. Des camps de réfugiés au gouvernement humanitaire. Paris: Flammarion, 2008.

AGIER, M.; MADEIRA, Anne-Virginie. Définir les réfugiés. Paris: Puf, 2017.

DALCASTAGNÈ, Regina. A personagem do romance brasileiro contemporâneo: 1990-2004". Estudos de Literatura Brasileira Contemporânea, Brasília, n. 26, p. 13-71, jul./dez. 2005a.

FIDALGO, António; CANAVILHAS, João (Org.). Comunicação Digital - 10 anos de Investigação. Coimbra: Edições Minerva, 2013.

KOSE, Osan .Agence française de presse. Disponível em: $<$ https://making-of.afp.com/>. Acesso em: 20 nov. 2018.

LE BLANC, G e BRUGERE, F. La fin de l'hospitalité (Lampedusa, Lesbos, Calais...jusqu'où irons-nous?). Paris: Flammarion, 2017.

JULIEN, François. L'écart et l'entre (Leçon Inaugurale de la Chaire sur l'altérité). Paris: Galilée, 2012.

MACE, Marielle. Ma colère veut aller vers plus d'amour de la vie, de la vie collective. In: TOURTE, Elise, Un Philosophe (Revue électronique de philosophie, de littérature et d'art), 27 nov. 2017. Disponível em: <https://unphilosophe. com/2017/11/27/entretien-avec-marielle-mace-ma-colere-veutaller-vers-plus-damour-de-la-vie-de-la-vie-collective-1-2/>. Acessível em: 27 nov. 2018.

MURARO, Cauê. Flip: sírio é vaiado por criticar Direitos Humanos e se nega a falar do EI. In: Jornal o Globo, 03/07/ 2016. Disponível em: <http://g1.globo.com/pop-arte/flip/2016/ noticia/2016/07/abul-said-e-vaiado-na-flip-ao-criticar-midiaintelectuais-e-direitos-humanos.html>. Acessível em: 20 nov. 2018.

NOUSS, Alexis. La condition de l'exilé (Penser les migrations contemporaines). Paris: Editions de la Maison des sciences de l'homme, 2015. 
SARMENTO, Tadeu. O Cometa é um sol que não deu certo. São Paulo: SM, 2017.

WHITOL DE WENDEN, Catherine. Migrations une nouvelle donne. Paris: Editions de la Maison des sciences de l'homme, 2017.
Recebido: 05/07/2018 Aprovado: 10/10/2018

(D) THIAGo OliveIRA Da MotTA SAMPaIO <leotonusbr@hotmail.com> Maître de Conférences habilité à diriger des recherches na Sorbonne Université. 